\title{
The Plasma Level of B-Type Natriuretic Peptide is a Useful Predictor of Cardiac Events for Out-Clinic Patients with Asymptomatic Heart Failure
}

Tojo $\mathrm{T}^{\mathbf{1}}$ and Yamaoka-Tojo $\mathrm{M}^{2 *}$

${ }^{1}$ Department of General Medicine, Sagamihara Kyodo

Hospital, Sagamihara, J apan

2Department of Rehabilitation, Kitasato University School of Allied Health Sciences, Sagamihara, J apan

*Corresponding author: Yamaoka-Tojo M, Department of Rehabilitation, Kitasato University School of Allied Health Sciences, 1-15-1 Kitasato, Minami-ku, Sagamihara 252-0373, J apan

Received: February 19, 2021; Accepted: March 04, 2021; Published: March 11, 2021

\begin{abstract}
Purpose: The circulating level of B-type Natriuretic Peptide (BNP) is recognized as a biomarker of ventricular dysfunction. In the field of primary prevention, BNP is a useful predictor of cardiac death, heart failure, cerebral infarction, and atrial fibrillation. On the other hand, the predictive value of BNP has not been fully elucidated in patients with coronary artery disease and/or those who are prone to atherosclerosis.
\end{abstract}

Methods: We analyzed 679 patients (average age, 65.3 years; 29.2\% women) with asymptomatic heart failure (ACC/AHA stage A to B) undergoing total risk management for cardiovascular disease prevention in the Kitasato Registry for Cardiovascular Disease Prevention. The mean follow-up period was 8.4 years (range, $73-3686$ days) for all study patients.

Results: Among all patients, $54.0 \%$ had coronary artery disease, $54.2 \%$ had hypertension, $55.7 \%$ had dyslipidemia, $31.2 \%$ had diabetes mellitus, and $15.5 \%$ had atrial fibrillation. The baseline level of plasma BNP was 47.5 (63.8) [mean (SD)] pg/mL. The plasma BNP level correlated with age and the serum creatinine level. The presence of coronary artery disease or atrial fibrillation significantly affected the plasma level of $B N P(P<0.05, P<0.01$; respectively). Plasma BNP levels were significantly higher in the event group than in the event-free group [80.4 (123.3) vs. $43.4(50.8) \mathrm{pg} / \mathrm{mL}, \mathrm{P}<0.0001]$. Of all patients, 59 experienced cardiac events and 10 died during the study period. In the multivariate analysis, plasma BNP level, age, and diabetes mellitus were identified as predictive factors. The Cox proportional hazards model showed that the plasma BNP level was an independent predictor of cardiac death. The event-free rate was significantly higher in patients with BNP of $40 \mathrm{pg} / \mathrm{mL}$ or less than in those with BNP of $40 \mathrm{pg} / \mathrm{mL}$ or more.

Conclusions: In the present long-term follow-up study, we found that the plasma level of BNP of patients who are in a stable condition was a useful prognostic marker. Circulating levels of plasma BNP could be an independent predictor of cardiac events in patients with asymptomatic heart failure.

Keywords: B-type Natriuretic Peptide; Atrial fibrillation; Atherosclerosis

\section{Background}

The circulating level of B-type Natriuretic Peptide (BNP) is recognized as a biomarker of increasing atrial and ventricular pressure and volume overloads $[1,2]$. Increasing plasma BNP levels are related to myocardial hypoxia $[3,4]$. In the field of primary prevention, BNP is a useful predictor of cardiac death, heart failure, cerebral infarction, atrial fibrillation, cardiac surgery [5], and ischemic heart disease [6$10]$.

Accumulating evidence revealed that BNP is an important indicator in risk stratification for patients with acute myocardial ischemia [11], with reduced event-free survival rate [12-14]. Circulating BNP concentration is associated with adverse long-term clinical outcomes among patients with Non-ST-Segment Elevation Acute Myocardial Infarction (NSTEMI) without Creatinine Kinase (CK) elevation (NSTEMI-CK) who considered low risk [15].
Although the usefulness of plasma BNP measurement for ischemic heart disease in the acute phase has been clarified, the predictivity of $\mathrm{BNP}$ as a prognosis biomarker in the chronic phase is controversial. In chronic patients with Coronary Artery Disease (CAD), the predictive value of BNP has not been fully elucidated [16]. The aim of the study is to examine whether or not the circulating levels of BNP could be a predictive biomarker in patients with CAD and/or those who are prone to atherosclerosis.

\section{Methods}

\section{Subjects}

The study included 679 Japanese patients of atherosclerosisprone or coronary artery disease with asymptomatic heart failure (ACC/AHA stage $\mathrm{A}$ or $\mathrm{B}$ ) undergoing total risk management for cardiovascular disease prevention in the Kitasato Registry for Cardiovascular Disease Prevention, Kitasato University East
Austin J Cardiovasc Dis Atherosclerosis - Volume 8 Issue 1 - 2021 ISSN: 2472-3568 | www. austinpublishinggroup.com Yamaoka-Tojo et al. @ A All rights are reserved
Citation: Tojo T and Yamaoka-Tojo M. The Plasma Level of B-Type Natriuretic Peptide is a Useful Predictor of Cardiac Events for Out-Clinic Patients with Asymptomatic Heart Failure. Austin J Cardiovasc Dis Atherosclerosis. 2021; 8(1): 1041. 
Hospital. The study project was approved by the Scientific and Ethical Committee of the Kitasato University School of Medicine, Japan. Patients were monitored for major adverse cardiac events and recurrences of CAD over a median 8.4 years.

\section{Blood sample collection and measurement of clinical biomarkers}

Blood samples were collected by venipuncture after an overnight fast from all patients. Biochemical markers, such as triglyceride, Low Density Lipoprotein (LDL) cholesterol, High Density Lipoprotein (HDL) cholesterol, plasma glucose, glycated haemoglobin (HbA1c), uric acid, Gamma-Glutamyl Transpeptidase ( $\gamma$-GTP), C - Reactive Protein (CRP), and BNP were measured in annual health checkup in the Kitasato East Hospital.

\section{Statistical analysis}

Continuous data were summarized as either mean \pm SD or median and quartiles, and categorical data were expressed as percentages. Data were compared by unpaired $t$-test or MannWhitney U-test where appropriate. Differences in proportions of variables were determined by chi-squared analysis. To evaluate the correlations between BNP and selected variables, we calculated Spearman correlation coefficients between circulating levels of BNP and other clinical biomarkers. Survival curves were estimated using Kaplan-Meier analysis. The cumulative incidence of all-cause death and Major Adverse Cardiac Events (MACE) for each biomarker was compared using log-rank test. A two-sided P value less than 0.05 was considered statistically significant.

\section{Results}

\section{Study population and patient characteristics}

A total of 679 patients in CAD or its prone, who have taken appropriate cardiovascular disease management with annual health checkup in Kitasato University East Hospital, were included (female 27.9\%). Comprehensive data on demographics, medical history, medication use, smoking status and anthropometric parameters including body mass index and blood pressure were recorded at enrollment.

Their median age was 66 years old, and average follow-up period was 7.9 years (median 8.4 years). All patients received evidence-based medical therapies and guideline-based instruction for cardiovascular disease management.

Among all patients, $54.0 \%$ had coronary artery disease, $54.2 \%$ had hypertension, $55.7 \%$ had dyslipidemia, $31.2 \%$ had diabetes mellitus, and $15.5 \%$ had atrial fibrillation. The baseline level of plasma BNP was $47.5 \pm 63.8 \mathrm{pg} / \mathrm{mL}$. The plasma BNP level correlated with age and the serum creatinine level. The presence of coronary artery disease or atrial fibrillation significantly affected the plasma level of BNP (P $<0.05, \mathrm{P}<0.01$; respectively). Plasma BNP levels were significantly higher in the event group than in the event-free group $(80.4 \pm 123.3$ vs. $43.4 \pm 50.8 \mathrm{pg} / \mathrm{mL}, \mathrm{P}<0.0001)$.

Baseline characteristics for patients with and without CAD are presented in (Table 1). The presence of hypertension, diabetes, dyslipidemia, smoking, and obesity, were high in CAD patients. Risk scores as total numbers of coronary risk factors, like as hypertension, diabetes, dyslipidemia, smoking and obesity, were high in CAD
Table 1: Baseline characteristics of the patients.

\begin{tabular}{|l|c|c|}
\hline & Non-CAD $(\mathbf{n}=\mathbf{3 0 5})$ & CAD $(\mathbf{n}=\mathbf{3 7 4})$ \\
\hline Age (years), mean \pm SD & $63.6 \pm 11.2$ & $65.9 \pm 9.9^{\star}$ \\
\hline Female (\%) & $116(38.0)$ & $80(21.4)^{\star}$ \\
\hline BMI $\left(\mathrm{kg} / \mathrm{m}^{2}\right)$ & $24.1 \pm 3.2$ & $24.3 \pm 3.7$ \\
\hline Medical History & & \\
\hline Hypertension $(\%)$ & $192(63.0)$ & $162(43.3)^{\star}$ \\
\hline Diabetes (\%) & $67(22.0)$ & $135(36.1)^{\star}$ \\
\hline Dyslipidemia (\%) & $135(44.3)$ & $232(62.0)^{\star}$ \\
\hline Risk Scores ${ }^{\Uparrow}$, mean \pm SD & $1.4 \pm 1.0$ & $2.6 \pm 1.0^{*}$ \\
\hline BNP (pg/mL), mean \pm SD & $38.2 \pm 40.9$ & $47.3 \pm 56.9^{*}$ \\
\hline HbA1c (\%), mean \pm SD & $5.3 \pm 1.3$ & $5.7 \pm 1.4^{*}$ \\
\hline Cr (mg/dL), mean \pm SD & $0.8 \pm 0.2$ & $0.9 \pm 0.5^{\star}$ \\
\hline
\end{tabular}

Mean \pm SD

*Statistically significant.

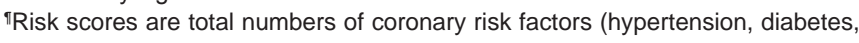
dyslipidemia, smoking, and obesity).

CAD: Coronary Artery Disease; BMI: Body Mass Index; BNP: Brain Natriuretic Peptide; Cr: Serum Creatinine.

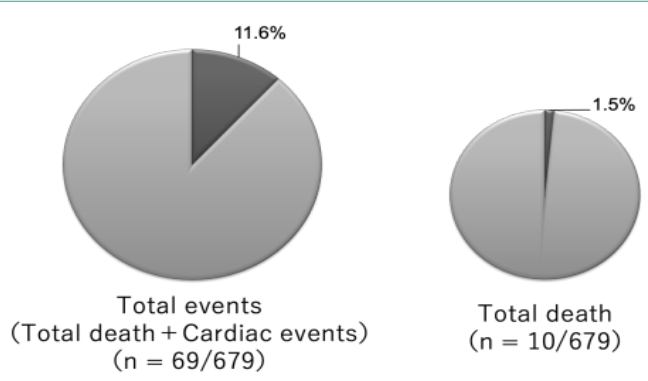

Figure 1: Proportion of total events and death during the study period in patients who registered in the Kitasato Registry for Cardiovascular Prevention. In total, 679 patients (female $27.9 \%$ ) were included and their median age was 66 years old. Average follow-up period was 7.9 years (median 8.4 years).

patients.

As expected, serum levels of $\mathrm{HbAlc}$, creatinine BNP were significantly increased in $\mathrm{CAD}$ patients compared with non-CAD patients. Serum levels of $\mathrm{HbA1c}$, creatinine BNP were significantly increased in $\mathrm{CAD}$ patients compared with non-CAD patients.

\section{Total events and death}

During the follow-up period $10(1.5 \%)$ died and 59 (8.7\%) patients experienced a cardiac event. during the follow-up period (Figure 1).

\section{Plasma BNP levels in patients with or without CAD}

The presence of CAD significantly affected the plasma level of BNP (Figure 2). Of course, history of hospitalization for heart failure or chronic kidney disease (CKD) also strongly correlated with circulating level of BNP. Plasma BNP levels had no correlated with CRP or white blood cell counts, which are general indicators of systemic inflammation (Figure 2).

Circulating plasma levels of BNP was significantly increased in CAD patients rather than non-CAD patients. Values are means (red line) P <0.05. BNP: Brain Natriuretic Peptide; CAD: Coronary Artery Disease. 


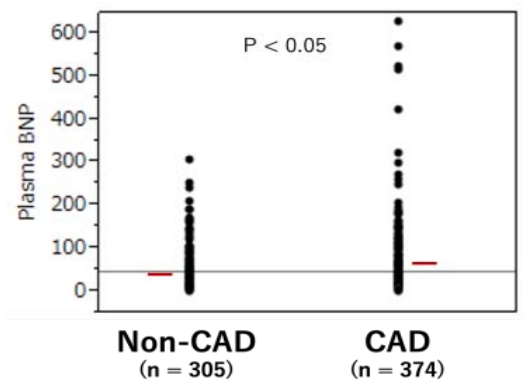

Figure 2: Plasma BNP levels in patients with or without CAD.
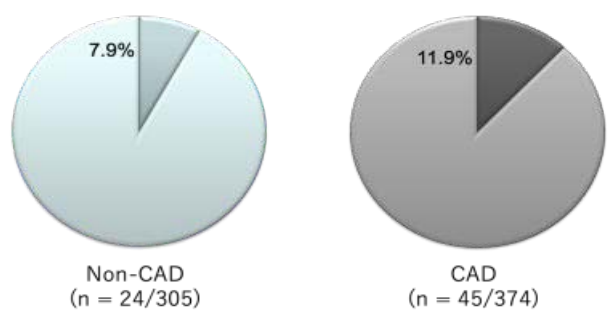

Figure 3: MACE in patients with or without CAD

\section{MACE in patients with adequate disease management}

Interestingly, the history of CAD was not affected cardiac events in the future between stable high-risk patients with atherosclerosisprone and stable CAD (Figure 3).

Figures show proportion of MACE (cardiac events and total death) during the study period in patients who registered in the Kitasato Registry for Cardiovascular Prevention. In total, 679 patients (female 27.9\%) were included and their median age was 66 years old. Average follow-up period was 7.9 years (median 8.4 years). CAD: Coronary Artery Disease; MACE: Major Adverse Cardiac Events.

\section{Plasma BNP levels predict cardiac events}

Plasma BNP levels were significantly higher in the event group than in the event-free group $(\mathrm{P}<0.0001)$. In the multivariate analysis, plasma BNP level, age, and diabetes mellitus were identified as predictive factors. The Cox proportional hazards model showed that the plasma BNP level was an independent predictor of cardiac death.

Subgroup analyses showed that BNP remained significant predictors of total death and cardiac events in patients without Diabetes Mellitus (DM) in multivariable models (Figure 4). Patients in the low BNP group are significantly higher events free rate compare

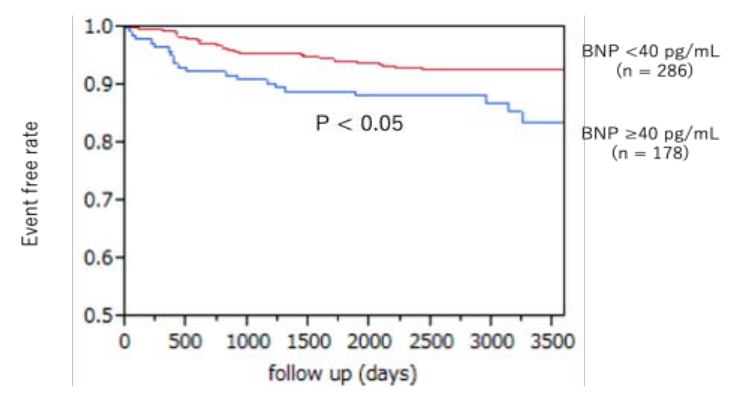

Figure 4: BNP predicts cardiac events in patients without diabetes mellitus. to those in the high BNP group.

The normal value of BNP is $18.5 \mathrm{pg} / \mathrm{mL}$ or less. Plasma levels of BNP are known to be elevated in patients with renal dysfunction, aortic valve stenosis, and hypertrophic cardiomyopathy. BNP, brain natriuretic peptide.

\section{Discussion}

The present study demonstrates that the presence of CAD significantly affected the plasma level of BNP. Besides, events free rate was lower in the group of high BNP (more than $40 \mathrm{pg} / \mathrm{mL}$ ) in non- DM patients, compare to those in the group of low BNP. Although further studies are needed to clear the usefulness of BNP measurement as a predictive biomarker for stable patients with atherosclerosis-prone or $\mathrm{CAD}$, in our data, around $40 \mathrm{pg} / \mathrm{mL}$ could be one of the important predictive value for these patients.

Plasma BNP concentrations are associated with cardiovascular risk in stable patients. Circulating BNP concentrations are elevated in heart failure or conditions with increased wall stress leading to left ventricular hypertrophy [17]. On the other hand, female sex and left ventricular volume were independent predictors of increased BNP [18]. In our participants, there were no significant differences of BNP levels between men and women.

Elevated levels of BNP are reflective of impaired cardiac function and is associated worse prognosis among patients with CAD [6,7]. BNP levels were independently associated with long-term mortality but nonfatal adverse ischemic or bleeding events in patients with left main CAD undergoing revascularization [19]. As a predictor of the prognosis of cardiovascular disease, it is thought that multiple BNP measurements can provide more information than a single measurement. Persistently elevated BNP levels may portend a worse prognosis than elevated BNP levels that subsequently decline or normalize [20,21].

In our study, elevated plasma BNP levels were independent predictors of MACE in CAD patients without DM. Consistent with our results, an elevated baseline BNP levels have been associated with a higher risk of cardiac events in patients with Impaired Glycose Tolerance (IGT) [22]. Among CAD patients without DM, a combination of cardiac biomarkers high-sensitivity troponin I and BNP yield the greatest predictive value beyond conventional risk factors [22]. In patients with myocardial infarction and IGT, high plasma BNP levels predicted the occurrence of coronary stenosis, recurrent myocardial infarction, and worsening of heart failure [23]. These results speculates that DM is a prominent factor to affect prognosis for $\mathrm{CAD}$ patients, and the presence of DM may brunt the predictive value of plasma BNP in patients with CAD.

\section{Conclusion}

In the present long-term follow-up study, we found that the plasma levels of BNP of patients who are in a stable condition was a useful prognostic marker. Circulating levels of plasma BNP could be an independent predictor of cardiac events in patients with asymptomatic heart failure.

\section{Acknowledgement}

This work was partly supported by JSPS Kakenhi grant number 


\section{JP19K11371.}

\section{References}

1. Ibrahim N, Januzzi JL. The potential role of natriuretic peptides and other biomarkers in heart failure diagnosis, prognosis and management. Expert Rev Cardiovasc Ther. 2015; 13: 1017-1030.

2. Omland T, Aakvaag A, Bonarjee VV, Caidahl K, Lie RT, Nilsen DW, et al Plasma brain natriuretic peptide as an indicator of left ventricular systolic function and long-term survival after acute myocardial infarction. Comparison with plasma atrial natriuretic peptide and $\mathrm{N}$-terminal proatrial natriuretic peptide. Circulation. 1996; 93: 1963-1969.

3. Goetze JP, Christoffersen C, Perko M, Arendrup H, Rehfeld JF, Kastrup J, et al. Increased cardiac BNP expression associated with myocardial ischemia. FASEB J. 2003; 17: 1105-1107.

4. May D, Gilon D, Djonov V, Itin A, Lazarus A, Gordon O, et al. Transgenic system for conditional induction and rescue of chronic myocardial hibernation provides insights into genomic programs of hibernation. Proc Natl Acad Sci USA. 2008; 105: 282-287.

5. Fox AA, Nascimben L, Body SC, Collard CD, Mitani AA, Liu KY, et al. Increased perioperative b-type natriuretic peptide associates with heart failure hospitalization or heart failure death after coronary artery bypass graft surgery. Anesthesiology. 2013; 119: 284-294.

6. Lindholm D, Lindback J, Armstrong PW, Budaj A, Cannon CP, Granger CB, et al. Biomarker-Based Risk Model to Predict Cardiovascular Mortality in Patients With Stable Coronary Disease. J Am Coll Cardiol. 2017; 70: 813826.

7. Bibbins-Domingo K, Gupta R, Na B, Wu AH, Schiller NB, Whooley MA $\mathrm{N}$-terminal fragment of the prohormone brain-type natriuretic peptide (NTproBNP), cardiovascular events, and mortality in patients with stable coronary heart disease. JAMA. 2007; 297: 169-176.

8. Omland T, Sabatine MS, Jablonski KA, Rice MM, Hsia J, Wergeland R, et al. Prognostic value of B-Type natriuretic peptides in patients with stable coronary artery disease: the PEACE Trial. J Am Coll Cardiol. 2007; 50: 205214 .

9. Kragelund C, Gronning B, Kober L, Hildebrandt P, Steffensen R. N-terminal pro-B-type natriuretic peptide and long-term mortality in stable coronary heart disease. N Engl J Med. 2005; 352: 666-675.

10. Schnabel R, Rupprecht HJ, Lackner KJ, Lubos E, Bickel C, Meyer J, et al. Analysis of $\mathrm{N}$-terminal-pro-brain natriuretic peptide and $\mathrm{C}$-reactive protein for risk stratification in stable and unstable coronary artery disease: results from the AtheroGene study. Eur Heart J. 2005; 26: 241-249.

11. Bibbins-Domingo K, Ansari M, Schiller NB, Massie B, Whooley MA. B-type natriuretic peptide and ischemia in patients with stable coronary disease: data from the Heart and Soul study. Circulation. 2003; 108: 2987-2992.

12. Iskander S, Iskandrian AE. Risk assessment using single-photon emission computed tomographic technetium-99m sestamibi imaging. J Am Coll Cardiol. 1998; 32: 57-62.
13. Shaw LJ, Berman DS, Maron DJ, Mancini GB, Hayes SW, Hartigan PM, et al. Optimal medical therapy with or without percutaneous coronary intervention to reduce ischemic burden: results from the Clinical Outcomes Utilizing Revascularization and Aggressive Drug Evaluation (COURAGE) trial nuclear substudy. Circulation. 2008; 117: 1283-1291.

14. Farzaneh-Far A, Phillips HR, Shaw LK, Starr AZ, Fiuzat M, O'Connor CM, et al. Ischemia change in stable coronary artery disease is an independent predictor of death and myocardial infarction. JACC Cardiovasc Imaging. 2012; 5: 715-724

15. Takahashi N, Ogita M, Suwa S, Nakao K, Ozaki Y, Kimura K, et al. Prognostic Impact of B-Type Natriuretic Peptide on Long-Term Clinical Outcomes in Patients with Non-ST-Segment Elevation Acute Myocardial Infarction Without Creatine Kinase Elevation. Int Heart J. 2020; 61: 888-895.

16. Oremus M, Raina PS, Santaguida P, Balion CM, McQueen MJ, McKelvie R, et al. A systematic review of BNP as a predictor of prognosis in persons with coronary artery disease. Clin Biochem. 2008; 41: 260-265.

17. Goetze JP, Mogelvang R, Maage L, Scharling H, Schnohr P, Sogaard P, et al. Plasma pro-B-type natriuretic peptide in the general population: screening for left ventricular hypertrophy and systolic dysfunction. Eur Heart J. 2006; 27: 3004-3010

18. Bing R, Henderson J, Hunter A, Williams MC, Moss AJ, Shah ASV, et al. Clinical determinants of plasma cardiac biomarkers in patients with stable chest pain. Heart. 2019; 105: 1748-1754

19. Redfors B, Chen S, Crowley A, Ben-Yehuda O, Gersh BJ, Lembo NJ, et al. B-Type Natriuretic Peptide Assessment in Patients Undergoing Revascularization for Left Main Coronary Artery Disease: Analysis From the EXCEL Trial. Circulation. 2018; 138: 469-478.

20. Zile MR, Claggett BL, Prescott MF, McMurray JJ, Packer M, Rouleau JL, et al. Prognostic Implications of Changes in N-Terminal Pro-B-Type Natriuretic Peptide in Patients with Heart Failure. J Am Coll Cardiol. 2016; 68: 24252436.

21. Hasumi E, Iwata H, Kohro T, Manabe I, Kinugawa K, Morisaki N, et al Diagnostic implication of change in b-type natriuretic peptide (BNP) for prediction of subsequent target lesion revascularization following silorimuseluting stent deployment. Int J Cardiol. 2013; 168: 1429-1434.

22. Wong YK, Cheung CYY, Tang CS, Hai JSH, Lee CH, Lau KK, et al. Highsensitivity troponin I and B-type natriuretic peptide biomarkers for prediction of cardiovascular events in patients with coronary artery disease with and without diabetes mellitus. Cardiovasc Diabetol. 2019; 18: 171.

23. Shindo K, Fukuda H, Hitsumoto T, Ito S, Kim J, Washio T, et al. Plasma BNP Levels and Diuretics Use as Predictors of Cardiovascular Events in Patients with Myocardial Infarction and Impaired Glucose Tolerance. Cardiovasc Drugs Ther. 2020; 34: 79-88. 